The Geneva Papers on Risk and Insurance, 18 (No. 69, October 1993), 375-387

\title{
A Japanese Perspective of Risk and Insurance
}

\author{
by Atsushi Inatomi*
}

\section{Introduction}

One of the fundamental principles of Property/Casualty Insurance is that a price can be attached to risks, both known and unknown. In Japanese the term risk is represented by two Chinese characters 「伦險」(pronounced ki-ken). Each character has an independent meaning. $\left\lceil\ell^{\prime}\right\rfloor(\mathrm{ki})$ denotes the situation of being on one's knees with fear as one overlooks a deep precipice, in short a state of being exposed.「陨」(ken) meanwhile denotes a deep precipice, i.e. the cause of one's being exposed. Thus, the word 「优除」(kiken) expresses the notions of both the state and the cause of being exposed.

In this paper I intend to approach the subject of Risk and Insurance from the perspective of a Japanese $\mathrm{P} / \mathrm{C}$ insurance professional.

\section{Risk and insurance}

\subsection{Report of the insurance council}

Insurance is the name we give to an agreement between an insurer and a policyholder such that the insurer promises to pay costs occasioned by a future unintentional loss on the part of the policyholder in exchange for a consideration in the form of premiums paid by the policyholder. If ever the insurer failed to honour this promise, the whole scheme of insurance would collapse. Due to its uniqueness, insurance business has been strictly regulated by the authorities in many countries. Recently, however, the view that more importance should be attached to the significant advantages for the consumer to be gained through the efficiency in a freer market, has gained ground.

In Regulation of the Insurance Markets, Prof. Dr. Lutgart Van Den Berghe presents a Magic Triangle Model (Stability - Regulation/Free Competition - Efficiency) which illustrates the problems confronting regulation of the insurance industry. According to the formula, in the insurance industry, stability is achieved by means of strict regulations whereas relaxing regulations enhances free competition, which in turn leads to efficiency. In Japan today, the balance on top of the magic triangle is leaning towards free competition.

* Managing Director International Operations, The Yasuda Fire \& Marine Insurance Company, Limited, Tokyo. 
Graph 1:

Magic Triangle Model

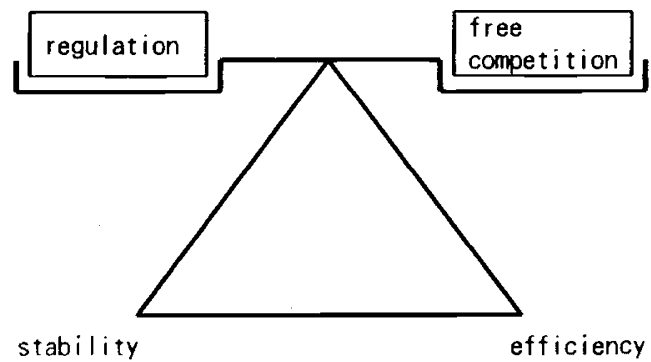

On June 17th, 1992, the Insurance Council of Japan submitted its final report entitled The New Course of Insurance Business to the Ministry of Finance, in which three principles were indicated, namely: 1 . Promotion of competition through deregulation; 2 . Preservation of soundness; and 3. Securing fairness in business operations. These demonstrate that the Japanese insurance market is heading towards liberalisation. The Insurance Council Report will be dealt with more fully in Chapter 2 of this paper.

The present chapter describes the various risks underwritten by insurers in Japan, though it would be impossible to discuss these risks without referring to liberalisation. Clearly liberalisation is a tendency in evidence all over the world as the steps towards deregulation in the EC insurance market demonstrate.

\section{Graph 2:}

$85 ¥$ trillions

Major Private Assets (stock)

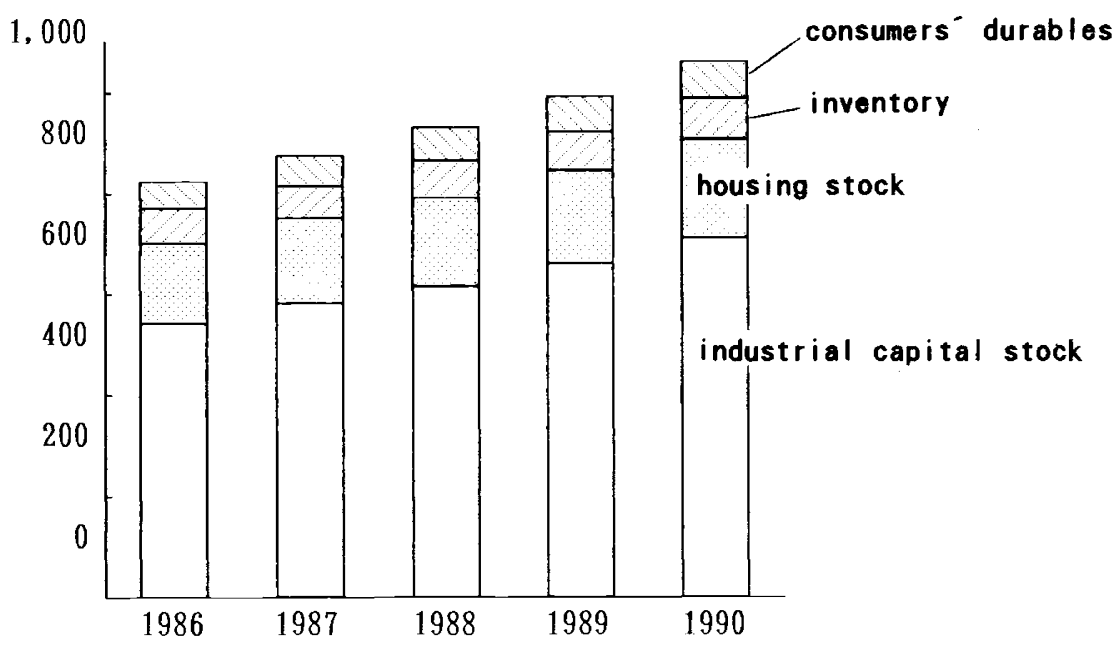

Source: Economic Planning Agency (1992). 


\subsection{Large risks}

The risks of today are generally characterised by their large size and diversity due to the substantial progress of the economy and society. Moreover, in Japan, as a result of economic progress, insurers are confronted with huge risks of a very different nature to those of the past.

\subsubsection{Risks of natural disaster}

a. Typhoon/Hurricane

In practice, hurricanes constitute one of the largest risks threatening insurers. Especially fresh in our memories is Hurricane Andrew, one of the most costly disasters in history, recorded as causing losses of more than $\$ 15$ billion. In September, 1991, Typhoon Mireille (or Typhoon No. 19 as it is known in Japan) caused a total loss of $¥ 700$ billion (\$6 billion), $¥ 500$ billion ( $\$ 4.6$ billion) of which were insured. The largest losses in 1991 were incurred on fire insurance lines due to the huge damage caused by this typhoon.

For that year, direct net claims on fire insurance came to $¥ 621$ billion in the case of householders and $¥ 149$ billion for factories and warehouses, up $305.5 \%$ and $259.2 \%$ respectively from 1990 .

Table 1:

Insured Losses for Typhoon Mireille ( $¥$ billion)

\begin{tabular}{|l|c|c|}
\hline line & number of cases & insured losses \\
\hline fire & 484,695 & 497.5 \\
\hline casualty & 12,568 & 25.1 \\
\hline automobile & $108,802^{*}$ & 26.9 \\
\hline marine & 1,256 & 18.0 \\
\hline total & 607,321 & 567.5 \\
\hline
\end{tabular}

* = number of automobiles

Source: The Marine and Fire Insurance Association in Japan, Incorporated (1992)

Because Japan lies geographically in the path of typhoons originating in the area of the Caroline and the Mariana Islands, it is actually subject to frequent typhoons. Even so, the scale of the losses caused by Typhoon Mireille was unprecedented. The reasons for the huge fire claims were:

(i) Fire insurance is widely held in Japan (in 1989, 50.4\% of Japanese households held fire insurance policies to protect their dwellings and household effects).

(ii) Ordinary fire insurance also covers windstorm damage and general fire insurance covers flood as well as storm damage. 


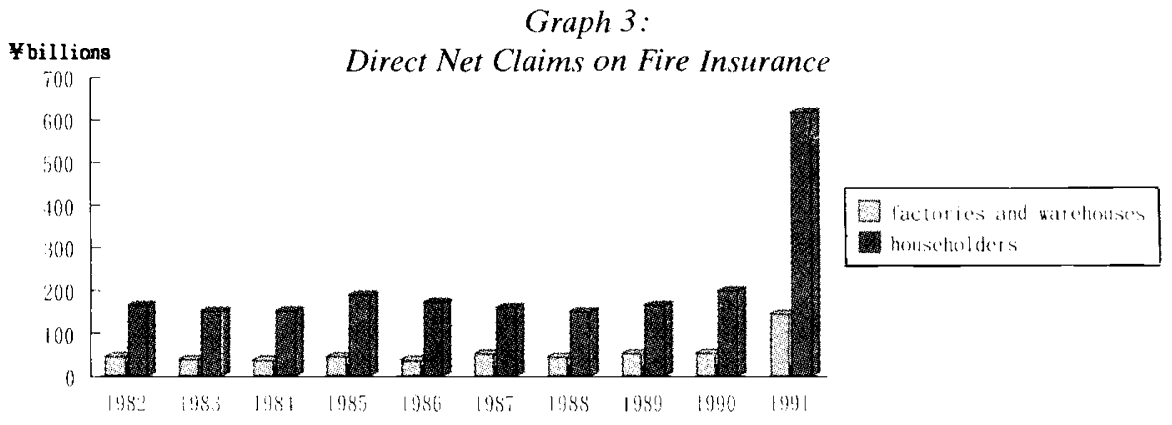

Source: The Marine and Fire Insurance Association of Japan, Incorporated (I992)

The insurance industry succeeded in fulfilling its social mission satisfactorily, issuing claims payments relatively swiftly through an efficient claims adjustment system facilitated by the prompt response of international reinsurers and in Japan by the establishment of claims service centres in the disaster areas and the mobilisation of large numbers of claims adjusters and inspectors from all over the country.

\section{b. Earthquake}

Severe earthquakes (of magnitude 6 to 8 on the Richter Scale) occur several times a year around the world. They pose a significant risk if and when they occur in the vicinity of large conurbations. Seventy years ago, the Great Kanto Earthquake of 1923 struck Japan, centering on Tokyo. This caused major damage and cost 150000 lives, and at an estimated one hundred thousand pounds (at least $\$ 50$ billion in today's money) goes down as the most expensive earthquake in history.

For technical reasons it is very difficult for private insurers to underwrite earthquake insurance. Problems include that it is difficult to collect data on the frequency of and the

Graph 4:

Flow of Earthquake Reinsurance

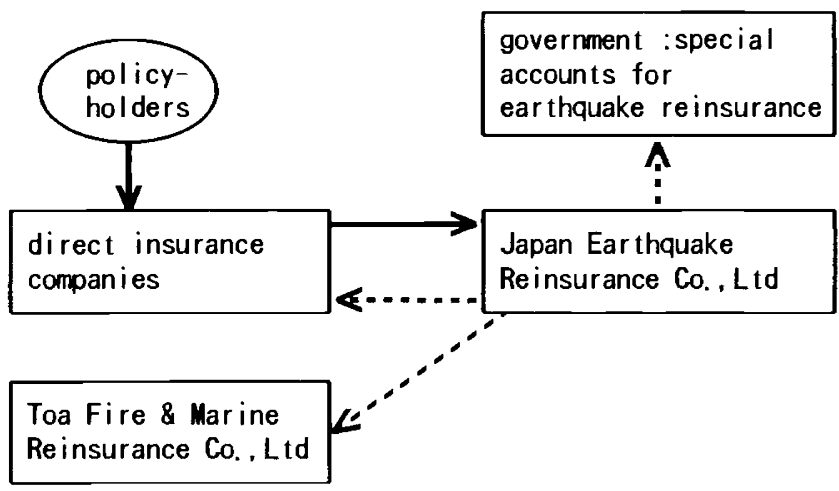


scale of damage caused by earthquakes; that earthquake insurance policyholders tend to be concentrated in high-risk areas; that it is difficult to arrange stable reinsurance; and most importantly of all, that the potential losses are enormous. In view of these points, earthquake insurance in Japan is structured in the following manner:

Firstly, a ceilling of $¥ 1.5$ trillion is set for the total liability of insurers with respect to a single earthquake. The existence of this limit is inevitable considering the potentially enormous scale of loss.

Secondly, the government operates a reinsurance system which comes into effect when loss exceeds a certain limit. The Japan Earthquake Reinsurance Company, Limited has been set up to specialise in reinsuring earthquake policies. All earthquake policies written by private sector insurers are initially ceded to this company, and thereafter reinsured once again with the government and private insurers (see over).

\subsubsection{Large risks caused by man}

In addition to natural risks, Mankind continues to face risks of its own making. The further Mankind progresses, the higher these risks become. Some of these risks threaten the very existence of Mankind itself.

\section{a. Nuclear risks}

Nuclear power has brought a new and formidable risk since it was developed in the 1940s. Today, in peace time, nuclear power functions as a source for the generation of energy over and above its original military purpose in nuclear warheads or nuclear submarines. Accidents at nuclear power plants serve to remind us of the terrible risks posed by nuclear power. In the accident at Three Mile Island of March 1979, a reactor generating 956000 kilowatts of electricity lost its coolants and the core of the reactor was almost melted down. This melting is known as the China Syndrome because if the core is actually melted down the nuclear fuel will burn through everything in its path until it reaches the other side of the earth.

Furthermore the April 1986 nuclear reactor accident at Chernobyl, a plant generating one million kilowatts of electricity released one billion curies of radioactivity. This is many times more than the Three Mile Island Accident and as much as the total released during past above-ground nuclear tests.

There are 40 nuclear plants generating 32.05 million kilowatts in Japan (as of September 1991) and 422 plants generating 343.41 million kilowatts in the worlds as a whole (as of June 1991). Direct insurers in Japan participate in the Japan Atomic Energy lnsurance Pool (JAEIP) and also in the worldwide cooperative scheme. These nuclear plants are subject to the safety regulations set out in the Basic Law of Nuclear Power under the supervision of MITI. As yẹt no major accidents have occurred.

\section{b. Acid rain}

Damage caused by acid rain in the EC has been widely reported in Japan. A study conducted by the Environment Agency in 1992 revealed that Japan is on a par with Europe with respect to this problem, with pH levels of between 4.3 and 5.3. At this stage Japan is not merely researching acid rain but actually implementing countermeasures to pre-empt detrimental effects on Japan's forests.

The causes of acid rain in Japan include industrial activities, exhaust fumes from motor vehicles, volcanic activity within the country in addition to industrial activity in neighbouring 
countries. Clearly some multi-national action is needed for comprehensive environmental protection. However, thus far in Japan, acid rain is not regarded as a risk suitable for insurance to handle.

Until recently, due to the causal link between acid rain and industrialisation, it is obvious that acid rain has only been the concern of the developed countries. However, acid rain has become a global concern affecting many developing countries. China is particularly badly damaged and the Chinese now speak of it as the "Devil of the Air".

\section{c. War}

In a sense, war risks are as old as Humanity itself. That being so, insurance has devised products to cover the risks of war. In Japanese marine insurance the rates are determined with reference to Lloyd's rates.

\subsection{The subject matter of insurance}

With the passage of time not only does risk grow in size, but so does its subject matter. Consequently when a large object is damaged, the damage incurred by the surroundings may also be considerable. Such is the case in the following examples:

\section{a. Aviation hulls}

At least in the case of civil aviation, the accident rate for aircraft is not higher than a decade ago. In fact statistics appear to indicate that the rate is decreasing. On account of the replacement of old planes with new models the capacity of both passenger and cargo planes is steadily growing. A jumbo jet is valued at $¥ 20$ billion ( $\$ 170$ million), which means the risk involved is extremely high. The JAL accident of August 1985, which cost 520 lives, a record number for a single air disaster, did not involve any third party personal or physical liability. The December 1992 cargo plane crash in the suburbs of Amsterdam demonstrates the horror of crashes in built-up areas.

\section{b. Spacecraft}

For several reasons, including their uniqueness and rarity, as well as technical evolution, vessels produced in the space development industry, such as artificial satellites and space shuttles, are becoming more expensive. In the case of Yuri II-B, launched in February 1986 , the total cost including relaunch costs came to as much as $¥ 16$ billion. Even unmanned rockets cost a huge amount. In the January 1986 explosion of Challenger, the total loss was reckoned to be about $\$ 1.5$ billion.

\section{c. Marine hulls}

Since the time of the Titanic, hull risks have been typical of large risks. In spite of the increasing volume of air transport, both hull and cargo prices have grown more expensive. In addition to the risks to the hull itself, the risk of incurring liability for damages is growing as in the case of oil tankers which cause environmental pollution in the form of oil slicks after an accident.

\section{d. Nuclear power plants}

Above (2.2.2.a.) we discussed the risks of nuclear power plants. In Japan, new plants with greater generating capacities oblige insurers to cope with ever higher prices. A state of the art plant can produce as much as 3 million kilowatts compared with only 1 million kilowatts for earlier versions. 


\subsection{New risks: conspicuous risks}

Another characteristic of risk nowadays is its diversity. This section discusses some examples of particular interest.

\subsubsection{Product liability}

Risks associated with product liability have been at the forefront since the 1970s. As a trading nation Japan has had to keep abreast of the developments in this respect in the countries to which it exports products, chiefly the U.S., collecting data and formulating risk prevention strategies.

It is appropriate to mention this risk because huge claims running into tens of millions of dollars have been incurred and because of the large number of these claims, as many as 100000 a year. Up until now, claims concerning product liability in Japan have been dealt with according to the notion of "negligence", one of the basic tenets of Civil Law, since there are no laws dealing specifically with product liability. Underwriting results for Product Liability insurance within Japan itself have been quite stable and not varied beyond a fairly narrow range. Of late, however, the demand for a strict liability law along the lines of that adopted in the EC has been growing and is being debated at the the National Social Policy Council, which is an advisory body to the Prime Minister.

Although it naturally depends on the content of the law, I doubt that a situation akin to that in the U.S. is likely to arise even if strict liability is included considering the differences in culture and legal processes between Japan and the U.S.

\subsubsection{Intellectual property}

Risks associated with intellectual property are still new to the market having reached the limelight in the 1980s, particularly in cases between U.S. and Japan. In the context of trade friction cases such as IBM vs. Fujitsu (1985) and Honeywell vs. Minolta (1987) have attracted much attention. It seems losses could run into hundreds of millions of dollars.

At present in Japan, liability insurance does not give indemnity in the case of a policyholder found guilty of infringement of intellectual property and insurers do not sell products to cover litigation costs. However, in the face of the conditions mentioned above, there seems to be an increasing demand from Japanese companies for Intellectual Property insurance so insurers are currently researching new products to address the demand.

\subsubsection{Overseas management risks}

Recently, risks associated with the overseas expansion of business activities by Japanese corporations have come to light, most conspicuously in cases of kidnapping, confiscations and taxrelated issues. It would seem that the causes of these risks include difference in culture (cultural aspects of employment) and corporate liability for the environment (notably that imposed under the Superfund Laws in the U.S.). Japanese insurers have yet to take measures to cope with such new risks.

\subsection{Further growth of large risks}

Having thus far given a rough profile of the large risks affecting society we will now go on to present our ideas on the questions of how we can expect these risks to change and what measures are to be taken to cope with these changes.

First of all, it is foreseeable that these risks will grow larger in scale. The risk proceeding from a single typhoon runs into billions of dollars and the cost of the failure of a 
single rocket launch as mentioned earlier easily exceeds $\$ 75$ millions. The world is likely to see a continued growth in population, national wealth and vast capital formations to support complex means of production. No reduction can be expected in the total volume of risks.

\subsubsection{Limitations on the capacity of insurers}

The insurance market has managed to absorb large risks by various coordinated underwriting schemes which thus avoid placing too heavy a burden on any individual insurer. Now that the scale of these risks is growing so enormous and that the demand for insurance against these risks is growing higher, the conventional insurance market is faced with difficulties in handling these risks which are well beyond its capacity.

\subsubsection{Gradually emerging risks}

The characteristic of conventional risks is that they are "accidental, sudden and external". However a new type of risks has emerged namely latent and gradual (creeping risks) which only become apparent with the passage of time. For example, acid rain causes gradual damage when it rains for a certain period of time and we cannot single out any one fall of rain as being actually and solely responsible for the damage. This is why acid rain is known as the "creeping murderer". Asbestosis is another example of a gradual risk. Through constant exposure to asbestos, people may develop malignant cancers of the skin and this has led to more than 60000 law suits for damages contested in U.S. courts. When people are exposed to excessive amounts of asbestos in the form of ultra-fine fibre particles (0.02-0.2 microns) they may suffer from cancer twenty or thirty years later. The asbestos they inhale clings to their lungs. For this reason the label "Silent bombs" has been given to asbestos. These risks are qualitatively different in the particulars of the risk and they are becoming more and more frequent.

\subsection{The growing need for international cooperation}

\subsubsection{Cross-border risks}

Large risks such as global environmental risks including acid rain, erosion of the ozone layer, and chemical contamination caused by such compounds as organic chloride and organic stannate, are neither originated in nor controllable by any single country. Concerted cooperation by both developed and developing countries and coordinated countermeasures on a worldwide level are essential. Three of the major causes said to be instrumental in speeding the deterioration of the global environment are extravagant consumption by affluent countries, economic development without heed to the environment in developing countries and poverty in developing countries. We are all crewmembers aboard Spaceship Earth and for this reason it is essential to tackle these massive global environmental risks through pooling information.

\subsubsection{Strengthening of the international reinsurance network}

In the assessment of large risks, underwriters usually examine the situation carefully, forecast the degree of danger scientifically through various data and then make a final decision.

The procedures taken will be the same even when the risks become larger. However, in the case of unprecedented risks, which are new to mankind, there are few clues or methods informing the underwriter's judgment other than scientific analysis and consequently the credibility of the judgment is impaired somewhat. The world reinsurance market 
has hitherto acted as a credible answer by absorbing these new risks, but of late it seems to have reached its limit. Particularly a series of disasters over the past few years including the Piper Alpha disaster in the North Sea oil field. Typhoon No. 19 in Japan and Hurricane Andrew in the U.S. has caused considerable damage in the market, to the extent that offers and renewals on various risks no longer run so smoothly. Thus, direct insurers worldwide are experiencing difficulties in obtaining reinsurance cover for large risks.

In view of these circumstances it is imperative that the overall capacity of the London Reinsurance Market, core of the world reinsurance market, be reinforced, and further that the world reinsurance market network, integrating the markets of Europe, North America, Asia and Oceania be considered so as to provide the direct market with sufficient capacity for these large risks. Moreover, at present the reinsurance market operates separately along each line of direct insurance (monoline) and in a different manner for each. Marine/aviation risks are generally reinsured on a multiple-line basis and in recent years non-marine risks have also tended to be reinsured in this way.

This leads to the conclusion that reinsurance as a market could be constituted integrally, rather than on a line for line basis. Insurance regulation and authorisation to write insurance in most countries is set out by line. Thus reform in this area would entail the prerequisite arrangements enabling the reinsurance market to effect "across-the-board" cover.

\section{Non-life insurance as an integrated financial institution}

In the previous chapter we reviewed the current situation and future perspective of large risks and various countermeasures available to the insurance industry including reinsurance. In this chapter, I would like to consider the likely changes and the circumstances desirable in the Japanese insurance industry in the future.

\subsection{Deregulation}

Deregulation will become increasingly prominent in the Japanese non-life insurance industry in the future. Up until now, the Japanese insurance industry has been regulated in its various aspects including management, products and distribution, in accordance with the demands imposed by its role in society and fairness. However, the insurance industry itself has been obliged to reform itself on account of the many changes which have occurred in the environment in which it is engaged. These environmental changes include:

a. The rapid aging of society (How should insurance deal with this change?).

b. Higher standards of living (Higher incomes increase the average level of assets per household, the need for diversified management of these assets, increased leisure time and the need for diversified leisure activities).

c. Changes in moral values and lifestyle (More emphasis on comfort, less on the supremacy of work).

d. The trends of globalisation, securitisation, computerisation in financial industries (Diversified financial products proceeding from increased sensitivity towards interest rates and the increase in the number of transactions taking place in the world).

e. Fair Business Practices (The need for a more transparent and user-friendly system).

f. Diversification of service needs (The need for various tailor-made specialised services). etc.

Furthermore the "enlarged and diversified risks" I mentioned in Chapter 2 are included in these changes. Deregulation is the most flexible way to handle these market changes. 
That is, reviews of regulation over products, fund management instruments and distribution in order to facilitate diversification and globalisation; and a review of the regulation pertaining to the scope of business permitted to affiliated companies to comply with the diversification of services.

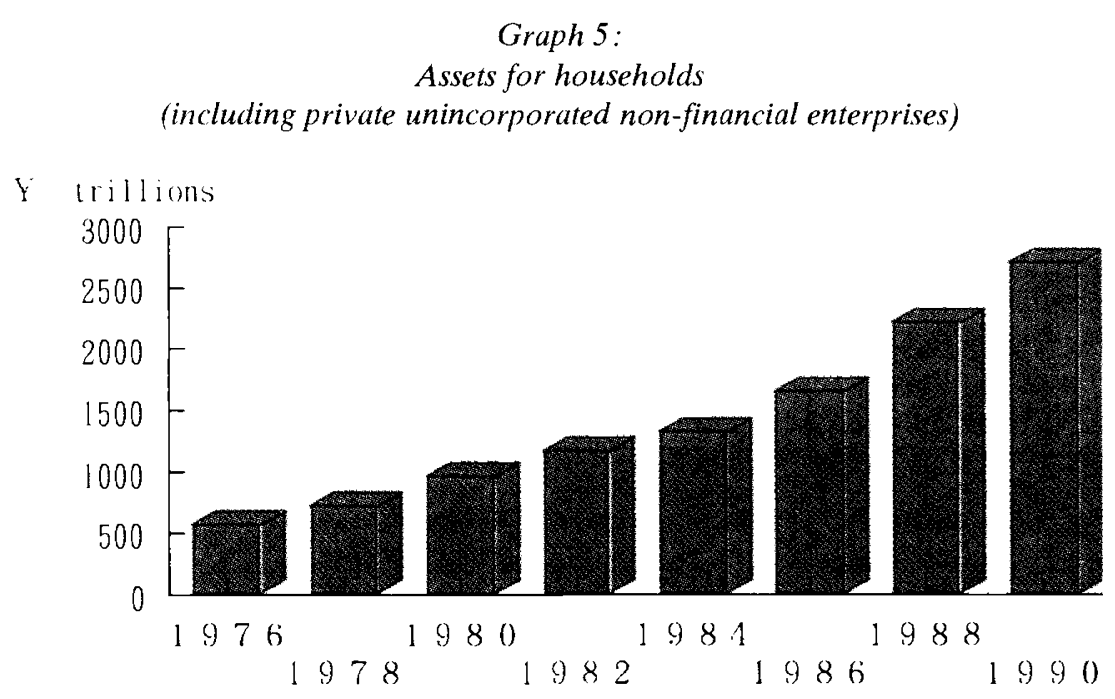

Source: Economic Planning Agency

\subsection{Mutual entry between life and non-life business through subsidiaries}

In June 1992 the Japanese Diet approved the Financial System Reform Act which will broadly deregulate Japanese financial industries. Under the new law financial institutions such as banks, securities companies and trust banks have acquired the right to enter into each other's businesses through subsidiaries in order to encourage competition. In the case of insurance the Insurance Council Report recommended that mutual entry be permitted between life and non-life companies through subsidiaries and preparations are now underway for a revision in the relevant law. In addition they proposed that the most appropriate way for insurance companies to enter other financial industries was also through subsidiaries.

Traditionally, mutual entry between life and non-life was prohibited because of the nature of the risks and the coverage term being very different. However, such reasons for prohibiting mutual entry were deemed to have declined in importance and the increasing similarity of the businesses was acknowledged in such fields as accident, sickness and nursing care insurance. These similarities became more apparent by dint of the amount of data collected in the past, the use of reinsurance and the higher dependence on savingslinked insurance products in the non-life industry. Consequently, mutual entry was recommended. 
The field of accident, sickness and nursing care insurance, originally known as the "third area" is the only field in which both life and non-life insurance companies are permitted to enter on their own accounts.

In order to achieve a proper practical separation of the two businesses, the use of subsidiaries was seen to be the most efficacious solution. This being so, it can be seen that the scope of opportunity for both life and non-life insurers is set to grow significantly, though with an equivalent expansion in the risks for both industries.

\subsection{Management risks of insurance companies}

As manifested by the mooted introduction of risk based capital standards in the U.S. and the E.C. Accounting Directives, progress is foreseen on securing the financial basis of the insurance company.

Since deregulation is set to be the norm in the Japanese Non-Life insurance industry from now on, now more than ever financial solidity will be essential to insurance companies.

Because management risks for insurance companies appear to be on the increase, in order to cope with them appropriately, the risk management systems of non-life companies must be bolstered. Augmenting the traditional means of achieving this, such as reserving and unrealised capital gains of stocks, the way forward this time will be to strengthen the solvency margin in excess of mandatory reserves.

\subsection{The aging society}

In the preceding three sections of this chapter, we considered the future direction of the Japanese non-life insurance industry. Next I would like to address the issue of how insurance should handle the demands of an aging society.

\section{Graph 6:}

\section{Population aged over 65}

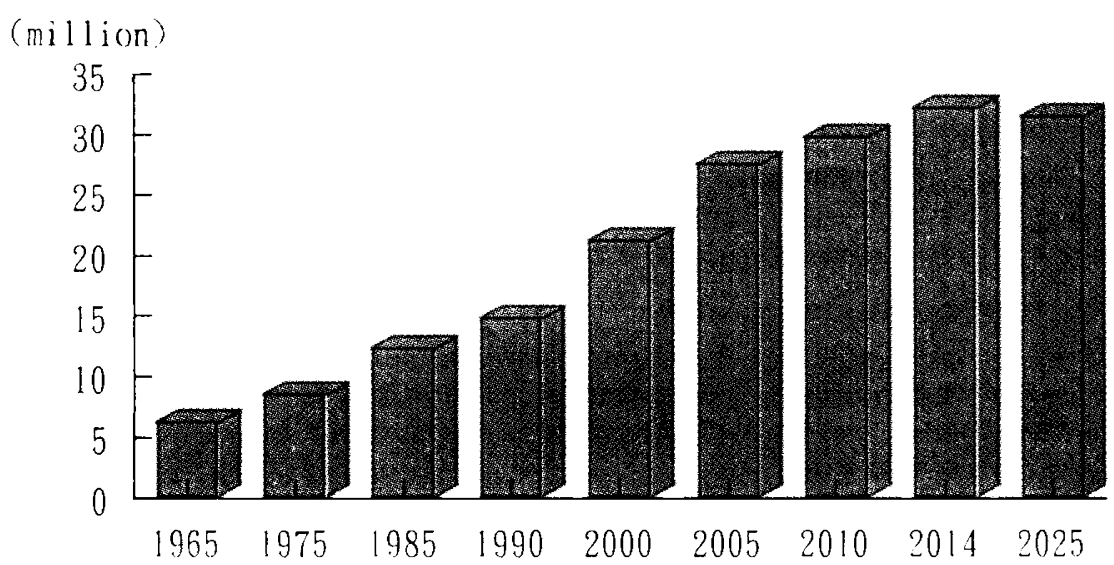

Source: Ministry of Health and Welfare (1992) 
In Japan the aging of society has advanced due to the combined effects of a decreasing birth rate and an increasing life expectancy. According to the Ministry of Health and Welfare, the percentage of the population over 65 is set to increase extensively over the next 30 years whilst that of the productive population between 15 and 65 is expected to drop significantly after 1995 . It is also worth pointing out that amongst all the advanced countries, Japan faces the most drastic aging of society (please see over).

This process, combined with the advent of the nuclear family and new trends in the causes of death, has given rise to a widespread anxiety amongst the population about the security of their retirement.

I believe it is a new challenge and a duty for non-life insurance to make headway in allaying the fears of ordinary people with respect to the future. More precisely, non-life insurance has tackled this problem by offering two new products, to wit:

\subsubsection{Non-life annuity-type products}

In an aging society, it is difficult to secure one's long-term income after retirement. Government pensions are at the heart of the social security system in their attempts to provide a solution for this problem. However, in the long term, the government pension system faces a stern challenge due to the declining birth rate and the prolongation of life expectancy. Ideas under discussion include raising the minimum age at which the pension may be paid (from 60 to 65 ) and reviewing the amount payable.

Under these circumstances, private pensions, which have been thought of as supplementary to the official pension scheme, are beginning to attract attentions and may be expected to play an important role in the future.

At present, private pension schemes are almost exclusively the domain of life insurance, with the non-life sector being proscribed from selling it. The non-life insurance industry has expressed an earnest desire to enter the market but the Insurance Council, after due consideration, decided to retain the present proscription except in the case of the establishment of a subsidiary.

Thus non-life insurers began selling non-life annuity-type products to respond to the needs of the consumer with savings-linked products with a longer maturity term on which the maturity return can be paid by installment on the basis of the underwriting result on accident insurance (November 1992).

However there are still some problems outstanding. These include firstly that for nonlife insurers a time limit must be applied to the maturity return and secondly that these products are ineligible for the tax credits normally applied to pension fund.

\subsubsection{Nursing care insurance products}

Elderly people confined to their beds or suffering from senility require a high degree of nursing care which society is finding increasingly difficult to provide. In 1989 , in order to address this problem, non-life insurance companies created nursing care insurance which covers the costs of such care.

Beyond merely paying for such care, non-life insurance gives the policyholders additional services such as providing information about nursing care suitable for policyholders or their families. Although at present we only provide financial support, we intend to extend actual support in the future. This would entail providing medical assistance, nursing care 
equipment or nursing staff. Through such measures we aim to calm people's worries about the future. This represents a new kind of risk for non-life insurers in that they have to perfect the management techniques suitable for a long term portfolio.

\section{Conclusion}

Changing mission of the insurer

Traditionally, man has coped with risk by retaining, transferring and diminishing them. Insurance is one of the means by which risk is transferred. As such our principal responsibility lies in handling the risk transferred to us by policyholders. This mission is achieved by providing the insurance products necessary to meet the needs of the people. I believe nonlife insurers should endeavour, by such means as the integration of the reinsurance markets, to cope with the growing risks which would have been difficult to underwrite in the current scheme.

However, as mentioned earlier, the market is currently going through a period of rapid changes in both the nature and the scale of risks. With the balance of the magic triangle tilted heavily towards international deregulation, non-life insurers must base their underwriting judgments first and foremost on their own financial strength. At the same time I believe we must strive to carry forward our efforts alongside insurers worldwide to establish a free and open market.

Given that the nature of risks basically reflects the nature of society, non-life insurers must be mindful of the responsibility of the industry as a whole to cope with re-arrangements in the infrastructure of society. Non-life insurers must address the requirements of its core business, that is handling risks, and furthermore, take a pro-active stance on the prevention of disasters through activities such as fire prevention programmes and accept the challenge to find effective solutions to the problems which cause people anxiety regarding the future wherever we find them. 